\section{Laser optometer incorporating the Badal principle*}

\author{
ROBERT T. HENNESSY and HERSCHEL W. LEIBOWITZ \\ The Pennsylvania State University, University Park, Pennsylvania 16802
}

The refractive state of the eye can be accurately determined while performing a visual task by introducing the diverged beam of a laser, reflected from a moving drum, into the visual field. The direction of the apparent motion of the resultant interference pattern is a direct indicator of refractive state. By incorporation of the Badal principle into the optical system, a measurement can be completed within approximately $30 \mathrm{sec}$. The advantage of this method over other techniques is that it permits evaluation of refractive state but does not itself influence the magnitude of accommodation. A number of applications of this principle are cited.

Measurements of eye movements have long been of interest to visual scientists. Significant contributions to theory have resulted from investigations of voluntary and involuntary eye movements, pupillary changes, and convergence (for a summary, see Alpern, 1971). However, relatively few studies concerned with the functional aspects of vision have been based on accommodation m e a surements. R a ther, accommodation studies have been more concerned with correction of refractive errors.

The principal reason that accommodative measures have been neglected with respect to functional aspects of vision is the difficulty of obtaining accurate and unbiased measurements of refractive state during performance of a visual task. Conventional methods of assessing refraction such as the use of the retinoscope, stigmatascope, and infrared optometer introduce undesirable conditions into the experiment. Retinoscopy requires that the $E$ place himself in the S's visual field. This is not only distracting, but can itself influence the accommodative state. Stigmatascopes require $\mathbf{S}$ to shift his attention to a small spot of light and to determine subjectively when it is in best focus. In effect, the $S$ is making direct estimations of his own refractive state. Infrared optometers require rigid positioning of the head usually by a biteboard, in order to insure the necessary critical alignment of the optical system with the S's eyes. This, in turn, leads to fatigue and necessitates a short observation session. In addition, the optometer may itself introduce extraneous changes in accommodation, i.e., instrument myopia (Baker, 1966;

*Supported by Grant MH 08061 from the National Institute of Mental Health. The authors are grateful to Dr. John A. Cegalis for his help and to Professor Lorance Harwood for a critical reading of the manuseript.
Schober, Dehler, \& Kassel, 1970; Shimojima, 1967).

The availability of low-cost lasers has provided a simple, inexpensive, and effective method of measuring accommodation which eliminates most of these objections. If the output of a laser is diverged, the appearance of the reflected beam is not uniform, but rather exhibits dark and light spots resulting from the constructive and destructive interference of the coherent beam. If $\mathbf{S}$ moves his head or the reflecting surface is moved with respect to $S$, this scintillation pattern may also appear to move, the direction of apparent movement depending upon the refractive state of the 0 . If the $O$ is focused in front of the scattering surface, i.e., myopia, the scintillation pattern will appear to move "against" the movement of the head. Conversely, if $O$ is focused beyond the surface plane, i.e., observed. If $O$ 's retina is conjugate with the scattering surface, no movement, or an indistinct swirling movement, is reported.

A number of investigators (Baldwin \& Stover, 1968; Knoll, 1966; Ingelstam \& Ragnarsson, 1972) have validated this technique by comparing results of retinoscopic refraction with data obtained by the laser scintillation technique. In all cases, high correlations between the conventional methods and the laser technique are reported, indicating that the laser is a valid and reliable method of measuring refractive state. Ingelstam and Ragnarsson have further verified the relationship between the focal state of the eye and the apparent movement of the granularity of the laser scintillation pattern in terms of physical optics.

In practice, the diverged beam from a low-energy laser is reflected from a slowly rotating drum to obviate the need for head movement. The $S$ views the target of interest through a beam splitter which superimposes the image of the laser scintillation pattern in the hyperopia, "with" movement is

field of view. A shutter located between the drum and the beam splitter permits presentation of the laser target for a brief exposure to avoid distraction by the constant presence of the scintillation pattern. By inserting lenses of appropriate strength between the laser and beam splitter, the direction of the apparent motion is eventually reversed. The lens strength that nulls the movement of the pattern or those strengths that bracket the reversal of motion are used to calculate the correction necessary to make the eye conjugate with the target of interest.

The utility of this technique has been demonstrated by a variety of studies. These include investigation of the influence of objects in the

peripheral visual field and the apparent distance of a fixation object on accommodative state (Hennessy \& Leibowitz, 1971), a replication of a previous study on the effect of accommodation and convergence, induced by prisms and lenses, on perceived size (Leibowitz, Shiina, \& Hennessy, in press). Another experiment utilized the laser technique to determine whether improvement in acuity resulting from hypnotic suggestion influences the refractive state of the eye (Graham \& Leibowitz, 1972). Studies were carried out at the Boeing Company in Seattle to determine the time required for pilots to refocus to a distant object outside the cockpit after looking at the instrument panel as a function of the distance of the panel illumination, and the age of the pilot (Larry \& Elworth, 1972). Experiments have also been conducted in the same laboratory to determine the change in accommodation as a function of convergence angle of the eyepieces of a microscope (Leibowitz et al, 1972). Present research in our laboratory is concerned with the effect of accommodation on the wearing of inverting and distorting prism spectacles (Cegalis, 1971) and the accommodative state under low levels of illumination, i.e., night myopia (Jackson, 1971).

In all these studies, the lens power that nulled or bracketed the reversal of apparent motion was determined by physically changing the lenses in the optical path of the laser beam. Rapid changing of the lenses was somewhat awkward. In addition, because of the distance of the lenses from the S's eye (usually about $2.5 \mathrm{~cm}$ ), a correction for the power of the lens at that distance had to be made. An undesirable factor results also from the variation in the size of the laser spot on the revolving drum with changes in lens strength.

These difficulties were overcome by combining the laser technique with the 


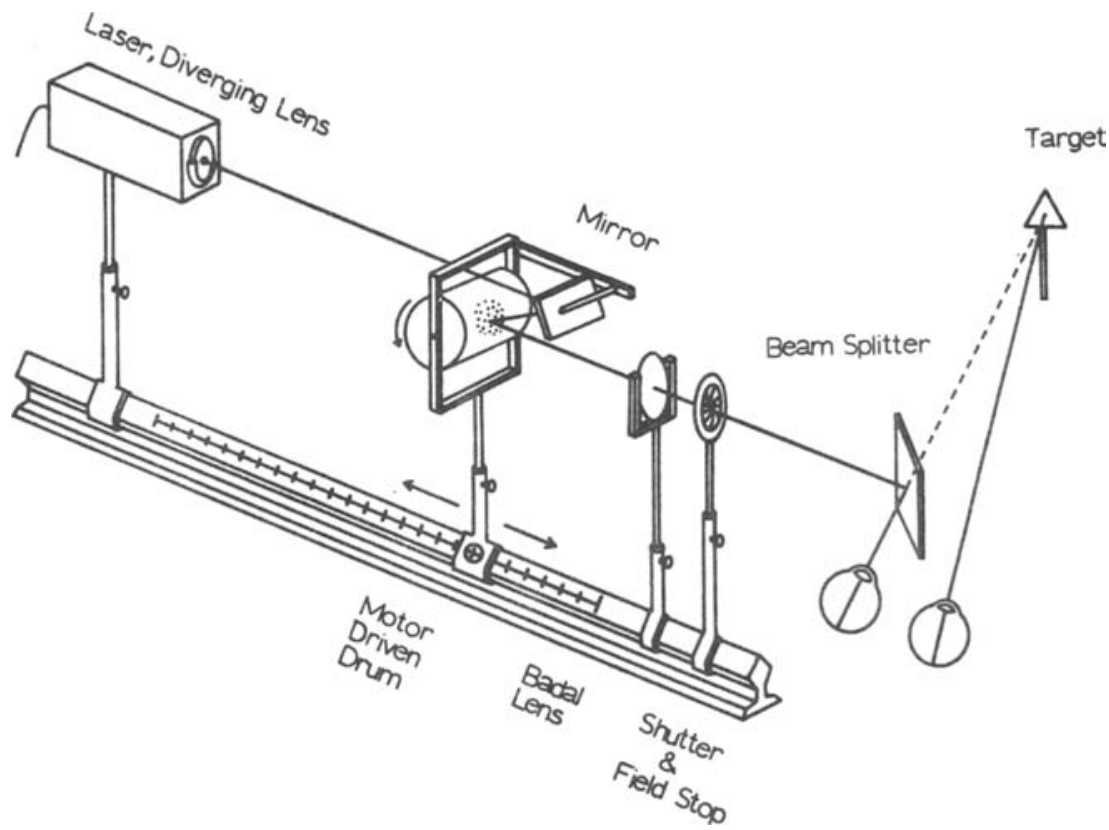

Fig. 1. Schematic diagram of the experimental arrangement.

principle of the Badal optometer. The Badal principle (Ogle, 1968; Southall, 1964 ) is based on the observation tirat if the eye is placed at the focal point of a positive lens, the virtual image of an object located between the lens and the anterior focal point will always subtend the same visual angle. However, the accommodation necessary to focus the image varies as a function of the distance of the object from the lens. When a target is at the anterior focal plane of the lens, the eye views its image at infinity. As the target approaches the lens, the image distance approaches the focal length of the lens. The relationship between the optical distance of the target image and the target position is given by the following formula: $Q=F^{2} u-F$, where $Q=$ the diopter value of image distance, $F=$ power of the lens in diopters, and $u=$ distance in meters of test target from lens. Further elaboration is available in Southall or Ogle. Incorporation of the Badal principle with the laser technique is accomplished by positioning the surface of the drum on the anterior optical axis of the lens. In this case, however, target distance, $u$, is measured between the lens and drum axis, not its surface (Ingelstam \& Ragnarsson, 1972). The drum is moved along the S's line of sight until reversal of the movement in the speckled pattern is reported. Distance to the axis of the drum from the Badal lens can then be converted directly into diopters by the above formula

In practice, the drum is mounted on a scaled optical bench. A photographic shutter is incorporated in the optometer optical path to restrict the image of the scintillation pattern to a brief exposure period, usually $.5 \mathrm{sec}$. This is done for two reasons: first, to allow the $S$ a clear view of the target of interest, and second, to avoid any possible stimulus to accommodation that the laser drum may offer. It has been previously demonstrated (Hennessy \& Leibowitz, 1970) that when the laser image is presented for $0.5 \mathrm{sec}$, there is no effect on accommodation. The optometer system also contains a variable field stop to restrict the angle subtended by the scintillation pattern. In order to keep the diverged beam of the laser aligned properly on the drum, a first surface mirror is mounted on an arm which extends above the drum and is attached to a common support. By locating the laser on line with the optical axis of the optometer with the beam aimed at the mirror, a nearly constant sized image can be maintained on the drum. The apparatus is shown schematically in Fig. 1.

The usual procedure is for the $S$ to sit in a chair with his head resting in a chinrest, viewing the target of interest through the beam splitter. The $S$ is instructed to fixate the target. The E then gives a warning signal to ensure that the $S$ maintains fixation on the principal target and opens the shutter exposing the laser pattern. The $S$ is asked to report whether the apparent movement of the granularity was either up or down. The $\mathrm{E}$ then moves the drum either forward or back. depending on S's responses, and repeats the above procedure. A bracketing technique is recommended in which the initial movements of the drum are rather large and become narrower, converging on the point of reported reversal. Typically, it takes between 20 and 45 sec to make a determination of refractive state.

This technique has proved to be a simple and efficient method of measuring accommodation, even for inexperienced Es. The objection can be raised that this technique has no advantage over the stigmatascope since a subjective report is required from the $\mathrm{S}$. The difference, however, is that with the laser optometer, $S$ is not required to make a judgment of focus. Instead, he is reporting the direction of a rather distinct movement, which, while related to the refractive state of the eye, is not influenced by how well $\mathrm{S}$ thinks he sees the measuring targets. It should also be noted that the present employment of this technique is primarily suited for finding relative changes in accommodation, i.e., the S's refractive state is measured at some base level, the experimental variable is introduced, and another measurement of refraction is made. Thus, only the change in accommodation is reflected in the difference score. If the absolute refractive state is desired, a correction must be made to compensate for axial chromatic aberration inherent in the monochromatic laser light.

In summary, the laser optometer described above provides a rather simple and accurate method for measurement of refractive state and changes of accommodation which may be used in a variety of experimental situations in which such measurements were heretofore impractical.

\section{REFERENCES}

ALPERN, M. Effector mechanisms in vision In J. W. Kling and L. A. Riggs (Eds.) Woodworth and Schlosberg's Experimental psychology. (3rd ed,) New York: Holt, Rinehart \& Winston, 1971.

BAKER, J. R. Experiments on the function of the eye in light microscopy. Journal of the Royal Microscopical Society, 1966 . 85, 231-254

BALDWIN, W. R., \& STOVER, W. B. Observation of laser standing wave patterns to determine refractive status. American Journal of Optometry, 1968 , 45, 143-150.

CEGALIS, J. A. Perceptual adaptation: An analysis of conflict. Unpublished doctoral dissertation. The Pennsylvania State University, 1971.

GRAHAM, C., \& LEIBOWITZ, H. W. The effects of suggestion on visual acuity. International Journal of Clinical \& Experimental Hypnosis, 1972, 20, 169-186.

HENNESSY, R. T., \& LEIBOWITZ, H. W. Subjective measurement of accommodation with laser light. Journal of the Optical Society of America, 1970, $60,1700-1701$.

HENNESSY, R. T., \& LEIBOWITZ, H. W. The effect of a peripheral stimulus on accommodation. Perception Psy chophysics, 1971, 10, 127-132. 
INGELSTAM, E., \& RAGNARSSON, S. I. Eye refraction examined by aid of speckle pattern produced by coherent light. Vision Research, 1972, 12, 411-420.

JACKSON, T. Subjective measurement of night myopia using optimum correction of visual and stereoacuity. Unbpulished master's thesis. The Pennsylvania State University, 1971.

KNOLL, H. A. Measuring ammetropia with a gas laser: A preliminary report. American Joumal of Optometry, 1966, 43, 415-418.

LARRY, C., \& ELWORTH, C. L. The effects of pilot age, lighting and head down time on visual accommodation. Boeing Technical Document No. D162-10378,-1 TN, 24 January, 1972.

LEIBOWITZ, H. W., SHIINA, K. \& HENNESSY, R. T. Oculomotor adjustments and size constancy. Perception \& Psychophysics, 1972, in press.

LEIBOWITZ, H. W., FARRELL, R. J. ANDERSON, C. D., KRAFT, C. L., \& BOUCEK, G, $P$, JR. The effect of a c commodation-convergence relationships on stereopsis. Optica Acta, 1972 , in press. (Abstract)

OGLE, K. N. Optics. (2nd ed.) Springfield,
Ill: Thomas, 1968.

SCHOBER, H. Über die Akkommodations ruhelage. Optik, 1954, 11, 282-290.

SCHOBER, H., DEHLER, H., \& KASSEL, R. Accommodation during observations with optical instruments. Journal of the Optical Society of America,a, 1970, 60, 103-107.

SHIMOJIMA, T. Eye accommodation when looking into the microscope. Japanese Journal of Clinical Ophthalmology, 1967, $21,785$.

SOUTHALL, J. P. C. Mirrors, prisms and lenses. New Yoxk: Dover, 1964. 